\title{
Mitochondria inspire a lifestyle
}

\author{
Peter Kramer (iD) and Paola Bressan \\ Dipartimento di Psicologia Generale, University of Padova, Italy
}

\begin{abstract}
Tucked inside our cells, we animals (and plants, and fungi) carry mitochondria, minuscule descendants of bacteria that invaded our common ancestor two billion years ago. This unplanned breakthrough endowed our ancestors with a convenient, portable source of energy, enabling them to progress towards more ambitious forms of life. Mitochondria still manufacture most of our energy; we have evolved to invest it to grow and produce offspring, and to last long enough to make it all happen. Yet because the continuous generation of energy is inevitably linked to that of toxic free radicals, mitochondria give us life and give us death. Stripping away clutter and minutiae, here we present a big-picture perspective of how mitochondria work, how they are passed on virtually only by mothers, and how they shape the lifestyles of species and individuals. We discuss why restricting food prolongs lifespan, why reproducing shortens it, and why moving about protects us from free radicals despite increasing their production. We show that our immune cells use special mitochondria to keep control over our gut microbes. And we lay out how the fabrication of energy and free radicals sets the internal clocks that command our everyday rhythms-waking, eating, sleeping. Mitochondria run the show.
\end{abstract}

\section{Keywords}

mitochondria, free radicals, antioxidants, circadian rhythms, dietary restriction, longevity

This is the authors' preprint of the article:

Kramer, P., \& Bressan, P. (2019). Mitochondria inspire a lifestyle. Advances in Anatomy, Embriology and Cell Biology, 231, 105-126. doi:10.1007/102_2018_5

Now, here, you see, it takes all the running you can do, to keep in the same place.

- Lewis Carroll, Through the Looking-Glass and What Alice Found There

\section{Pump or perish}

Mitochondria were once bacteria that invaded one-cell creatures from another domain of life, and that happened to let out as waste precisely those gasses that the host creatures used to sustain themselves (Martin et al 2016). The cohabitation went spectacularly well and the guest bacteria ended up relinquishing part of their genetic material to the host cell-which out of it built a control center, a "nucleus"-while keeping only a few genes to themselves.

\section{Corresponding Author:}

Peter Kramer or Paola Bressan, Dipartimento di Psicologia Generale, Università di Padova, Via Venezia 8, 35131 Padova, Italy. E-mail: peter.kramer@unipd.it or paola.bressan@ unipd.it 
This unplanned breakthrough endowed the hosts with a convenient, portable source of energy, making it possible for them to evolve into more ambitious forms of life (of which we are one).

From their bacterial ancestor, mitochondria have inherited the ability to produce energy via an intricate mechanism whose details differ little across the various kingdoms. Digested food is burned to fuel a machine that, from ADP (adenosine diphosphate) and an extra phosphate, forges ATP (adenosine triphosphate). The freshly coined ATP is then dispatched from the mitochondrion to the host cell. Wherever the cell needs it, energy is released from ATP by stripping it of a phosphate. This leaves behind ADP and phosphate, that within the mitochondrion can be recharged to ATP again. What is exquisitely elaborate is how mitochondria put the plan into effect.

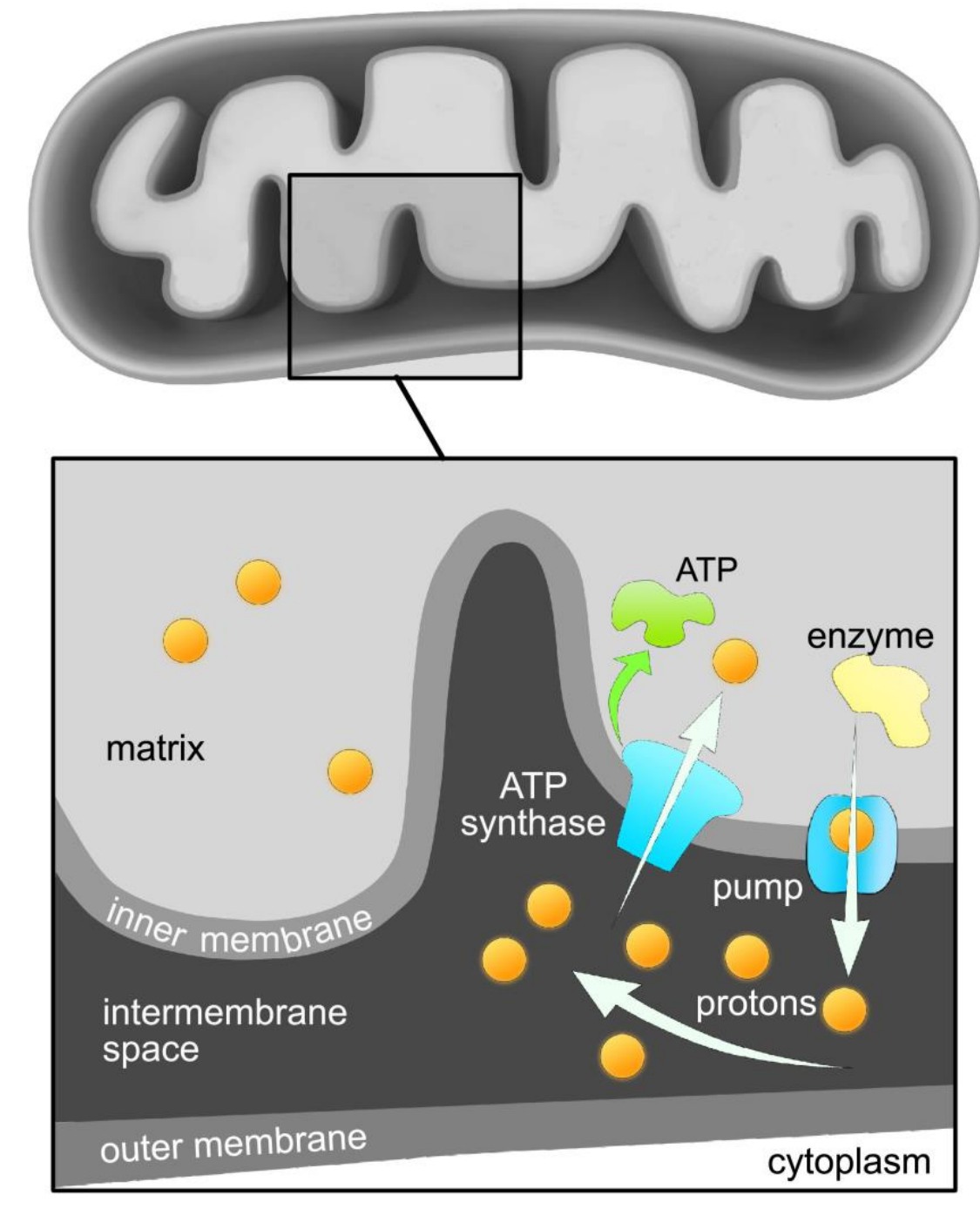

Fig. 1 Schematic, simplified representation of a mitochondrion. Inset: in the matrix (light gray), an enzyme (yellow) delivers protons (orange) and electrons stripped from digested food to a proton pump (blue shape on the right; electrons and additional stations are not shown). The flow of electrons within the pump provides the energy to make it transfer protons from the matrix to the intermembrane space (dark gray). The protons can then return from the intermembrane space to the matrix via the ATP synthase (mushroom-like blue shape on the left). In the process, the ATP synthase is pressed into service and produces ATP (green). Image source: Bressan (2018). 
Each mitochondrion features a fairly smooth outer membrane, that separates the mitochondrion from the rest of the host cell, and a much more convoluted and interesting inner membrane; together they enclose the intermembrane space (Figure 1). The inner membrane is important enough that an average human carries $14,000 \mathrm{~m}^{2}$ of it (Rich 2003). Plugged through the membrane are complexes, minuscule pieces of machinery dedicated to the job of ATP generation; a single mammalian mitochondrion accommodates legions of them, perhaps in the order of 30,000 (Lane 2005). These are organized into sets of four consecutive stations. In the space in the middle of the mitochondrion, the matrix, equal numbers of protons and electrons are stripped from the molecular remains of digested food; the electrons are separated from the protons and fed into the first machine, called complex I. From there, the electrons are shuttled along the inner membrane through two further stations ${ }^{1}$ and finally disgorged back into the matrix, where they are sucked up by oxygen.

The passage of electrons along the membrane only serves to power the passage of protons across it - which is indeed the whole point of the arrangement. Making its way within each station, an electron creates disturbances that end up opening, one after the other, a series of channels across the membrane. Each channel stays open just long enough to let a proton pass through and shuts closed right behind it. The end result is that the protons are transferred from one side (the matrix) to the other (the intermembrane space) of a membrane that is otherwise sealed off to them. For every pair of electrons that reaches the end of the chain to be snatched up by oxygen, ten protons have been pumped across the membrane.

Each proton carries one positive charge. Thus, the amassing of protons on one side of the membrane produces a large difference in electrical charge, with the outside (the intermembrane space) becoming strongly positive relative to the inside (the matrix). The voltage difference across the membrane amounts to one tenth of that of an alkaline watch battery, but because the membrane is extraordinarily thin, we are talking about an electric field strength in the order of 30 million volts per meter, much like a bolt of lightning (Lane 2005). As the number of protons builds up, the difference in proton concentration and electrical charge between the two sides tends to pull the protons from the intermembrane space to the matrix. Protons are held back by the membrane at all places, however, except at specific stations ${ }^{2}$. Each of these stations accommodates one ATP synthase, a molecular machine impressively similar to man-made rotary motors, except that, with a velocity of up to several hundred revolutions per second (Ueno et al 2005) and an efficiency of very nearly $100 \%$ (Omote et al 1999), it outperforms them all. An ATP synthase removed from a bacterium and integrated in a nickel nanopropeller has been shown to power it splendidly (Soong et al 2000), suggesting that the fabrication of nanomachines from live biological materials is the stuff of science fiction no longer (Strong 2004).

The ATP synthase looks a bit like a mushroom with a rotating stalk embedded within the mitochondrial inner membrane and a head protruding into the matrix. Protons make the stalk rotate by flowing through channels in it, and this movement turns - a third of a full rotation at a time - a stalk-connected rotor sitting within the head. This sequence of turns prompts the head to perform a fixed sequence of operations. At the first turn the head clasps ADP and phosphate; at the second it forces them together to make ATP; at the third it

\footnotetext{
${ }^{1}$ Only two, because one of the four stations is just an alternative entry point for electrons.

${ }^{2}$ Some protons are allowed to leak back into the matrix through pores in the membrane. This transfer reduces the difference in proton concentration on either side of the membrane and dissipates as heat part of the energy that was pent up in it. In warm-blooded animals, this comes in handy to maintain body temperature (Brand et al 1991).
} 
releases the newly-formed ATP (Boyer 1975). A full rotation requires 10 protons and delivers 3 molecules of ATP. The ATP can now leave the matrix, through a dedicated transporter embedded in the membrane that grabs the ATP molecule on the matrix side and deposits it on the other side - a result similar to that achieved by a bank's sliding security doors. The portal is now ready to do the same job in reverse: receive ADP via the open external door, lock it in and release it on the matrix side by opening the internal door. A separate entrance admits phosphate; upon reaching the matrix, ADP and phosphate are on call to be recharged to ATP again.

When all is well, the electrons flow smoothly down the route to oxygen by hopping from one site to the next, in single file, within each complex. But if they are too slow, the chain becomes clogged up with them; each is unable to move on because the next site is already taken. This can happen, for example, when there is no ADP left in the cell to be converted into ATP, perhaps because ATP is not being consumed fast enough and is thus not broken down into ADP again. An electron stuck in the chain can escape from it onto an oxygen molecule or another chemical nearby. All chemicals contain one or more nuclei, made of protons and neutrons, and a number of electrons orbiting around them. While circling around, each electron spins around its own axis and typically has a companion electron that spins in the opposite direction. By sucking up an extra electron from the electron transport chain, the chemical acquires an unpaired electron, and this turns it into a free radical.

Free radicals are extraordinarily corrosive, first and foremost to the mitochondrion that produces them but also to the cell that hosts the mitochondrion and, by extension, to the organism that hosts the cell. Free radicals have a way of reacting with whatever molecules happen to be nearby, including mitochondrial genes which in this way accumulate damage by collecting mutations. An avalanche of free radicals thus bodes no good, but mitochondria have evolved to use it as a smoke alarm - a signal that electrons are not being transferred properly along the chain. In fact, complex I might be deliberately set up so that electrons can leak from it at the slightest hint that the chain is blocked (Lane 2015). In response to a massive release of free radicals within it, a mitochondrion strives to take countermeasures. For example, it can increase the number of respiratory complexes so as to raise ATP production and tailor it to demand, or it can divide and multiply. If demand cannot be met, the inept mitochondrion may go on to commit suicide, freeing space for newcomers, or, if its host cell has incurred too much damage, it may proceed to kill the entire cell. The vital feedback role of free-radical leakage in improving mitochondrial function can help explain, as we shall later see, why antioxidants supplements not only fail to prevent disease but can be downright dangerous.

\section{All about Eve}

Despite that $99 \%$ of mitochondria's components are manufactured by around 1500 nuclear genes and $1 \%$ by 13 mitochondrial ones (Rahman and Rahman 2018), it is mitochondrial genes that oversee the control system of energy production (Johnston and Williams 2016). Just like local matters are best left to local rather than national governments, local diversity in energy requirements is best addressed by genes in the locally active mitochondria rather than by those in the faraway nucleus. In response to a smoke alarm, for example, the cell nucleus would have no clue as to which particular mitochondrion is responsible and thus needs to be upgraded or replaced. 
Mitochondrial genes do sit very close to where energy is locally produced. Unfortunately, this means they also sit very close to where free radicals are locally released, hence they might accumulate mutations faster than they would if they were stationed in the nucleus. ("Might", because mitochondrial genes appear to be physically shielded and painstakingly defended from such assaults: Kauppila and Stewart 2015.) Because mitochondria do get heavily tarnished with use, it comes as something of a surprise that those that are inherited by each new generation tend to carry no damage whatsoever. Every bit as surprisingly, the mitochondria that do get passed on-in the vast majority of species including ours - come entirely from mothers (Pyle et al 2015). Together, human mothers and fathers hand down a set of about 20,000 nuclear genes; in addition, the fertilized egg houses 100,000 live mitochondria (Jansen 2000) exclusively from the mother, each featuring multiple sets of 37 mitochondrial genes.

To make sense of these two surprises, it has been proposed that the mitochondria in egg cells are prevented from ever producing any energy and are simply kept in storage (Allen 1996; Allen and de Paula 2013; de Paula et al 2013). They will be used as templates for producing new mitochondria after transmission to the offspring; in female embryos, some of them will be sequestered away in the eggs sitting in the tiny, still developing ovaries. These pristine mitochondria will then be passed on to the next generation-and so on and so forth, from mother to daughter. Eggs may afford to waive active mitochondria because they do nothing much, and can thus subsist on energy coming from less efficient sources or from the mitochondria of adjacent cells in the ovary. Sperms cells, instead, cannot just sit around; they must swim as fast as they possibly can to arrive first and get to fertilize the egg cell. Their mitochondria must deliver a flawless performance, at the cost of getting corroded by free radicals in the process. Thus, whereas egg cells can keep their mitochondria pure and fresh, sperm cells cannot.

To be prevented from being passed on, sperm mitochondria are labeled as unworthy right from the start and are promptly destroyed when they run into the egg's destruction machinery (Sutovsky et al 1999). Apparently, the harm that they would do to the offspring is so great that fathers cooperate biologically in having them all dismantled upon arrival in the egg. Across species, indeed, a staggering diversity of techniques (Sato and Sato 2013) has evolved to dispense with male mitochondria (including that of defecating them soon after birth: Pitnick and Karr 1998), suggesting that selection pressures favoring uniparental inheritance appeared on the scene repeatedly and independently. One wonders if the problem is only with paternal mitochondria being subpar, or if inheriting two different sets of mitochondrial genes is undesirable in and of itself. Through manipulation and selective breeding it has been possible to answer this question by forcing mice to inherit two perfectly healthy, but different, sets of mitochondrial genes. Interestingly, these mice turn out to be physiologically, emotionally, and cognitively worse off than mice that, other things being equal, inherit just one set (Sharpley et al., 2012).

Assisted reproductive technology may unwittingly force human babies to inherit dissimilar mitochondrial DNA too (e.g., Hiendleder 2007; Sutovsky et al 1999). Some of these techniques aim to prevent the transmission of mitochondrial disease from mother to child by introducing a twist in the practice of inserting the eggs of a healthy donor into the womb of an unhealthy recipient. Before implantation, the nucleus of each donated egg is replaced with the nucleus removed from an egg of the recipient (Herbert and Turnbull 2018). The recipient can thus pass along to her children all of her own healthy nuclear genes, but none (ideally, because perfection is not of this world) of her unhealthy mitochondrial ones. Babies born with the help of these techniques have effectively three biological parents- 
having inherited only nuclear DNA from their father, (hopefully) only nuclear DNA from their mother, and only mitochondrial DNA from another, donor mother.

Even disregarding that these babies are likely to get some of their mitochondria from the wrong mother, the trouble is that the nuclear genome from one mother and the mitochondrial genome from the other might not cooperate properly (Hiendleder 2007). The apparently risible percentage of mitochondrial components encoded by the mitochondrial genome includes most of the building blocks of the electron transport chain; the remaining are produced by the nuclear genome (Johnston and Williams 2016). Thus, a less than perfect interaction between the two genomes could alter the nanoscopically precise distances between the sites through which the electrons pass down the route to oxygen, impairing their flow-with more or less catastrophic consequences (Lane 2011). Only time will tell how the health and lifespan of people with three parents measure up to those with just two.

Incidentally, the fact that mitochondrial (unlike nuclear) DNA never gets mixed with that of fathers makes it uniquely suitable for tracing people's ancestry along the female line. Following our progenitors' mitochondrial footprints back from mother to grandmother to great-grandmother, one arrives at Mitochondrial Eve, a title currently held by a woman who gave birth to her own daughters around 200,000 years ago (Cann et al 1987) and from whom all people alive today descend in an unbroken female line ${ }^{1}$.

\section{All creatures great and small}

How much an organism needs to eat depends on how fast it converts food into energy. This metabolic rate depends on whether the organism is moving or not and on what its characteristics are, such as whether it is cold or warm blooded, what sexual strategy it likes better, and how big it is (Lane 2005). Yet not all body parts demand an amount of energy that is proportional to the organism's overall size (Haldane 1926). In larger land mammals, for example, bones - which require little energy to maintain - are relatively wider, but the blood vessel system is less dense, with each capillary feeding a greater number of cells, and this allows the heart to beat more slowly, saving energy (Lane 2005). Indeed, larger species spend energy more efficiently: food and oxygen consumption per gram of body weight diminish with size, along with the breathing, heartbeat, and metabolic rates (Lane 2005). The lower the metabolic rate, the lower the production of free radicals per cell and per mitochondrion-and thus the lower the risk of early degeneration and death. Indeed, large species tend to outlive small ones (Blagosklonny 2013): a lucky mouse has a life expectancy of two or three years, an elephant of sixty or seventy.

Large species spend their energy more efficiently than small ones, grow to maturity more slowly, and-perhaps counterintuitively - feature lower levels of growth hormones (Stuart and Page 2010; Swanson and Dantzer 2014; Tian et al 2017). Within a species, however, all individuals mature about equally fast, thus larger adults must have grown faster than smaller ones. Individuals' final size is likely to reflect an inclination towards promoting or inhibiting the hormonal mechanisms that sustain growth; indeed, larger adults have higher levels of growth hormones (Bartke 2017; Swanson and Dantzer 2014).

\footnotetext{
${ }^{1}$ Other women were around at the time and also earlier, of course, but their own mitochondrial lineages happened to become extinct. Some of these women may well have descendants alive today, yet not in a direct female line but passing, at some point or other, through a male (a dead end for mitochondria).
} 
The problem with growth is that it depends on cell divisions and each division requires the copying of DNA. Every round of copying increases the probability of mistakes (mutations) and, with it, the probability that growth spins out of control, leading to cancer. Larger species, that in principle would be most vulnerable to cancer, actually invest more than do smaller species in mechanisms dedicated to fighting it (Tian et al 2017). For example, elephants have 20 copies of a gene that forces cancer cells to commit suicide, whereas humans and mice have 1 copy only (Sulak et al 2016). As it happens, genetically modified mice with an extra copy develop fewer tumors (Matheu et al 2007).

Whereas individuals of larger species are better protected against cancer than those of smaller ones - which cancels the costs of being big-larger and smaller individuals of the same species have identical defenses in place. In line with this, taller men are more likely to suffer from cancer, and tend in general to die earlier, than shorter men (He et al 2014). Tellingly, the manufacturing of an important growth hormone appears downregulated in both human centenarians (Suh et al 2008) and their offspring (Vitale et al 2012). If growth hormones are diminished artificially, an experiment that has been tried in a kind of roundworm (Zarse et al 2012), cells suck in less glucose from the blood; starved of sugar, they must switch to less preferred fuels, such as those derived from fat. So, they have no choice but to rely even more heavily on mitochondria than they usually do, because only mitochondria can make ATP by burning fat. This surge in mitochondrial activity is accompanied by a modest increment in free radical levels, which in turn prompts antioxidant defenses that reduce these levels to values below those seen before the intervention. The net effect is that the worms age more slowly and end up living twice as long as usual (see also Miller et al 2018; Schulz et al 2007).

One can achieve similar results in creatures other than worms by simply offering them no more food than necessary. In rodents, for example, restricting food intake reduces the level of the chemical that feeds electrons into the electron transport chain, the escape of electrons from the chain, and the formation of free radicals (Barja 2013). As a rule, eating adequately but less than desired postpones the diseases of aging and prolongs life in organisms ranging from yeast to fish, from spiders to humans (Fontana et al 2010). In humans, these benefits also apply to people who are not considered overweight to start with (Redman et al 2018).

Eating less than preferred is very hard. With this truth in mind, dietary regimes have been proposed that do not restrict calories but still lower the levels of glucose, like ketogenic diets, or those of growth hormones, like diets that curtail the consumption of protein or some critical component of it. Ketogenic diets feature plenty of fats such as cream and butter but very little carbohydrates, our main source of glucose, and thus conveniently mimic fasting (Longo and Mattson 2014). Lack of sugar pushes the liver to break down stored fat into molecules called ketone bodies, which mitochondria can use for fuel (e.g., Newman and Verdin 2014). Ketone bodies, likely as an adaptive response to nutrient scarcity, also intensify the recycling of damaged cell components and similar debris, which may serve as emergency food for the cell (Camberos-Luna et al 2016). Perhaps because it removes potentially lethal garbage, this frenetic housekeeping might be another reason why ketogenic diets appear to ameliorate a variety of afflictions, ranging from neurological diseases to cancer (Branco et al 2016; Gano et al 2014; Kramer and Bressan 2018; Miller et al 2018).

Ketogenic diets drastically cut out carbohydrates but reduce protein too, on the grounds that protein could otherwise be converted into glucose. This measure may have an accidental further advantage, because restricting protein-or at least two of its most common component amino acids - appears to promote health and longevity in itself (Dong et al 2018). 
These two amino acids are methionine and cysteine (methionine restriction being largely ineffective if cysteine is not removed too: Wanders et al 2015). Methionine is an essential amino acid, one that cannot be produced by the body but must be introduced with the diet, and the ability to sense its deficiency and promptly respond to it is of course indispensable to survival. As is often the case with indispensable activities, multiple mechanisms appear to be in place to achieve the same purpose. A major one involves the liver, that within hours of a methionine-restricted meal increases 5-fold its production of a fundamental metabolic regulator (Forney et al 2017a).

This regulator proceeds to orchestrate a suite of adaptive responses that include a coordinated increase in energy intake (likely on the lookout for extra methionine, one eats more) and expenditure (Anthony et al 2013). The latter is achieved mainly by making the mitochondrial inner membrane leakier to protons, so that some of the energy pent up in the intermembrane space, rather than being used to make ATP, is wasted as heat (Hasek et al 2010). As a consequence, the production of free radicals drops, and with it drops the damage that free radicals inflict on tissues and DNA (e.g., López-Torres and Barja 2008). It may be no coincidence that species that live longer, such as the pigeon, happen to carry less methionine in their flesh than species that live shorter, such as the rat. In mammals - from mice to horse, through rabbit and pig - the negative correlation between methionine content in the heart and maximum lifespan is nearly perfect (Pamplona and Barja 2006).

Despite ingesting more food, animals on methionine-restricted diets stay thin because the cost of growth increases: more energy is required for maintaining existing tissue (Hasek et al 2010). Yet a cost is a cost, and while the degree of restriction that compels individuals to take in more food proves salutary, going just a bit further down that road causes excessive weight loss: animals become thinner and thinner but stop consuming extra food, as though methionine is now so low that eating more would make no difference (Forney et al 2017b). An even stricter dilution of any essential amino acid creates (within minutes: Hao et al 2005) an aversion to the unbalanced food, and, if no alternative source can be tracked down, simply fails to sustain life. More of a good thing is not always a better thing.

\section{Have kids, die early}

Periodic famines may be one reason why we animals eat more than we need. Another may be that stern diets inhibit the immune system, impairing wound healing and recovery from infection; reduce the response to cold, increasing mortality in small animals when temperature drops; and diminish bone and muscle mass, potentially hindering one's ability to fight or escape from predators (Adler and Bonduriansky 2014). All of this saves energy, but - except under lab conditions - bodes ill for survival. Yet the most important reason why we desire more food than necessary may be that eating is not just about sustaining ourselves but also about producing offspring. The hormones and enzymes that encourage growth in response to nutrient abundance reduce lifespan but also upregulate hormonal mechanisms that bolster fertility and sexual activity (follicle-stimulating hormone, luteinizing hormone, estrogen, and testosterone); hormones and enzymes that reduce growth do the opposite (Ellison 2017; Templeman and Murphy 2018).

Within species, individuals that invest more in acquiring mates and producing offspring tend to die earlier (Lemaittre et al 2015). This is also the case in humans: reproductive success (measured as either a larger number of children or shorter birth intervals) is associated with reduced survival in both women and, to a smaller extent, men-even after adjusting for socioeconomic status and other potential confounds (Penn and Smith 2007). Rounding off 
this evidence, both male and female centenarians have fewer children than other people and had them later in life (shown in Ashkenazi Jews: Tabatabaie et al 2011). Thus, the survival costs of reproduction go beyond the physical burdens of pregnancy, childbirth, and breastfeeding.

Achieving reproductive maturity requires development and growth, and the amount of growth that has taken place is reflected in individuals' size. Indeed, dwarf people resemble centenarians (who, as mentioned earlier, manufacture less growth hormone) in that they reproduce later in life (Bartke et al 2013; Hull and Harvey 2014). In dwarfs, the odds of developing diabetes and cancer are also lower than average, whereas in giants they are higher and accompanied by a reduced life expectancy (Bartke 2017). In mice bred to be dwarfs, which do not have enough of a particular growth hormone, fertility is either abolished or delayed, but lifespan is stretched by up to 50\% (Bartke et al 2013). Female hyenas with low levels of growth hormone in their youth tend to be smaller as adults, but even when they are not, they breed later and live longer (Lewin et al 2017).

Intriguingly, in humans (like in several other animals), low maternal food intake has been associated with a greater likelihood of giving birth to females than to males, and women who gain less weight during gestation produce fewer sons (Navara 2014; see also Myers 1978; Trivers and Willard 1973). The main reason appears to be that sons tend to be larger than daughters and hence require more resources, even in the womb: more male than female fetuses are spontaneously aborted when food is scarce. Women who became pregnant during the great Chinese famine from 1957 to 1961, which killed 30 million people, were less likely to give birth to sons than expected (Song 2012; Song 2015); the same happened during the 1974 famine in Bangladesh (Hernández-Julián et al 2014).

Growth, reproduction, and longevity are also interrelated in another interesting way. Different species have different strategies regarding the quality and quantity of their offspring (Lane 2015). Those enforcing the strictest quality control discard as defective the most egg cells and spontaneously abort the most of their potential offspring. This results in fewer but healthier offspring that can survive longer. Those producing more offspring are forced to lower their quality control standards, but then their offspring tend to die sooner. It is a species' circumstances that appear to dictate its strategy. For example, creatures that fly require more energy than those that do not, and this calls for better mitochondria and therefore for higher quality control of offspring. A pigeon delivers 15 young per year and a rat 60, but then the pigeon's lifespan is ten times longer than the rat's.

Demonstrating that mitochondria play a critical part in such survival strategies, beetles that are artificially selected for either long or short lives, and respectively breed later or earlier, end up with distinctly different types of mitochondrial DNA (Stojković et al 2017). From an evolutionary point of view, of course, it is better to live a short life yet reproduce than to live a long one but leave no descendants. In this respect, the fact that mitochondrial DNA does not care about its effects on males has occasionally a silver lining for them. For example, a type of mitochondrial DNA found in fruit flies renders females fertile but shortlived and males sterile but long-lasting (Camus et al 2015).

\section{Guarding the gate}

We are not alone in our bodies; we house some 38 trillion microbes (Sender et al 2016) belonging to at least 2,172 known species (Hugon et al 2015). Our health depends also on theirs (Gilbert et al 2016; Kramer and Bressan 2015; Rogers et al 2016) and so does the health of our mitochondria. Most of these microbes live in our gut and are heavily affected by 
the food we eat. For example, protein is mostly digested by enzymes in our nearly sterile small intestine. The rest progresses to the colon, where it is fermented by bacteria that expel, as waste products, toxins like hydrogen sulfide (Linden 2014; Pal et al 2018; Yao et al 2016) - the gas that gives rotten eggs their foul smell. Some vegetables, like cauliflower and broccoli, have evolved an abundance of sulphur compounds to ward off their own parasites (Björkman et al 2011). Such compounds harm the bacteria in our gut that disgorge hydrogen sulfide (Kellingray et al 2017), opening up opportunities for rival, beneficial ones; which might be part of the reason why a regular consumption of this family of vegetables is associated with a lower probability of developing diabetes, cardiovascular diseases, and cancer (Björkman et al 2011).

Hydrogen sulfide is not entirely bad; some of our cells assemble it in small amounts from cysteine and use it, for example, to send important messages to other cells (Banerjee et al. 2015). Still, the more protein we eat, the more hydrogen sulfide we get; eventually, it may become too much. If so, the gas can tear open the mucus layer that protects the gut wall, breach into the wall's cells, and harm their mitochondria (Blachier et al 2007; Mottawea et al 2016). This chain of events raises the mitochondria's free radical production-which in turn increases the permeability of the barrier that separates the gut from the bloodstream (Mottawea et al 2016), granting entry into the body to those microbes, viruses (Pal et al 2018), and potentially immunoreactive food particles (Bressan and Kramer 2016) that are normally held back inside the gut. It is no wonder that specific assortments of gut microbes have been associated with disorders of every description (Bastiaanssen et al 2018; Gilbert et al 2016; Kramer and Bressan 2015; Rogers et al 2016).

The task of keeping pathogens confined within the gut is delegated to the immune cells that line its inside. Curiously, these cells get their energy from mitochondria whose electron transport chains are embedded in an unusual variant of the inner membrane- one that is purposely fashioned to limit energy production (Konjar et al 2018). In response to the inflammatory signals triggered by an infection, the properties of this membrane suddenly change: the brakes come off and energy production shoots up to full capacity. Now the immune cells get a jolt of energy and multiply rapidly to attack any pathogens that may be hanging about. The concomitant increase in free radical levels, which is indeed typical of inflammation (Angajala et al 2018; López-Armada et al 2013), helps wrecking the pathogens further. The mitochondria with the unusual membranes are thus effectively gatekeepers: they keep a large number of guard dogs (the immune cells) under control when all is well, but set them loose when evil characters (the pathogens) arrive on the scene. With the gut's immune cells under the control of mitochondria and the immune cells themselves always at beck and call to assail gut microbes, it makes a lot of sense that differences in mitochondrial DNA are associated with differences in gut microbe composition (Clark and Mach 2017; Hirose et al 2017). In an overt attempt to overcome an immune response against them-a response which is invariably assisted by a hefty release of free radicals - several pathogens discharge toxins that interfere with their host's mitochondrial signaling and overactivate its antioxidant mechanisms (Clark and Mach 2017).

Indeed, every so often our frontline troops are not up to the task and we need to destroy the pathogens ourselves. In most societies, few go through life without ever taking antibiotics: globally, just over the period 2000-2015, their consumption has increased by $65 \%$, reaching nearly 35 billion doses per day (Klein et al 2018). Although they can be indispensable occasionally, antibiotics famously wipe out beneficial gut bacteria along with offensive ones-allies and enemies both-and worsen the balance between them after recovery (Keeney et al 2014). On top of that, antibiotics harm mitochondria very directly, 
because of course mitochondria resemble bacteria, their forebears. Even at recommended doses for the recommended time, antibiotics injure the outer wall and DNA of mitochondria, upset their quality control activities, and disrupt electron transport chains-making them produce less energy and more free radicals (Kalghatgi et al 2013; Wang et al 2015). Whatever hurts microbes - most prominently, common pesticides and pollutants (KaramiMohajeri and Abdollahi 2013; Meyer et al 2013; Mostafalou and Abdollahi 2013) — is indeed likely to hurt mitochondria. In our fight against pathogens and pests, we ought to be much more careful about collateral damage to our tenants.

\section{A call to (some) action}

During the day we eat; digested food is stripped of electrons and these are fed into the transport chain to make fresh ATP. Yet if we do not move, not much ATP is broken down into ADP, and our ATP synthases run out of supplies. When ADP is unavailable, the ATP synthase stops and protons can no longer flow, through it, into the matrix (Wallace 2005). As the protons accumulate inside the intermembrane space, their increasing concentration impedes further pumping of protons into this space. The pumping slows down, and the stream of electrons through the electron transport chain slows down with it. Electrons continue to be fed into the chain, however; as they heap up, more and more of them escape before reaching their final destination (shown in vitro: Herrero and Barja 1997), react with oxygen, and form free radicals.

By consuming ATP and thus speeding up the flow of electrons, exercise hence decreases (rather than increases, as one might have thought), the formation of free radicals inside mitochondria. But mitochondria are not the only source of free radicals; these are fabricated in various chemical reactions elsewhere too, and during exercise their net level goes up, not down (He et al 2016; Powers and Jackson 2008; Trewin et al 2018). If one exercises regularly, the body puts into effect a suite of countermeasures to be ready to cope with similar stresses in the future (Goto et al 2007; Gradari et al 2016; Hood et al 2011). Such countermeasures include the upregulation of repair mechanisms and the production of both antioxidants and enzymes meant to get more glucose out of the blood and into cells (reducing, incidentally, the risk of diabetes). They also include an upgrade in the number of mitochondria and of the electron transport chains inside them. This has an antioxidant effect because the more chains there are, the fewer electrons can be fed into each-per unit of food burned down-and thus the fewer electrons leak out to form free radicals. Somewhat counterintuitively, then, the beneficial effects of exercise turn out to be due (albeit indirectly) to a rise in free radical levels.

Motivated by the wish to do the right thing, many healthy people - athletes prominently included-exercise (which raises free radical levels) and take antioxidant supplements (which lowers them). Yet antioxidant supplements turn out to block the health-promoting effect of exercise (Merry and Ristow 2016; Peternelj and Coombes 2011; Ristow et al 2009; Villanueva and Kross 2012). The harmful effects of the free radicals produced by exercise are compensated - surpassed, in fact - by the countermeasures they trigger, and this is why exercise is healthy after all.

Note that this holds when exercise is moderate. When it is excessive, free radical levels may increase too much for benefits to outweigh costs (in which case taking antioxidants might even be fine: Radak et al 2017, though not wearing oneself out seems like a better plan). As it happens, rats that are forced to swim either 10 or 30 minutes a day for 20 weeks develop fewer mutations in their mitochondrial DNA than rats who remain idle (Cao et al 
2012). Yet, whereas rats that swim for 10 or, better, 30 minutes a day end up with more copies of mitochondrial genes (associated with greater resilience), rats that swim for 60 or 90 minutes end up with fewer. Similarly, in humans, overtraining has been associated with considerable free-radical damage to fat tissues, proteins, and DNA (Radak et al 2008; Radak et al 2013).

It stands to reason, then, that the effects of exercise depend on how much one is biologically capable of generating energy and on how easily one produces free radicals. Both traits are determined, in part, by the type of mitochondrial DNA one has inherited from one's mother. For example, carriers of one type manufacture more ATP and free radicals than carriers of another (Martínez-Redondo et al 2010). Interestingly, Olympic endurance athletes (such as swimmers, cyclists, long-distance runners, and cross-country skiers: Maruszak et al 2014) tend to carry the former type.

\section{There is a time for everything}

Unexpectedly, the production of energy and regulation of free radical levels have popped up as crucial in the supervision of a still largely mysterious activity in which we engage about a third of our time: sleep. For the past decades, researchers of biorhythms (recurring cycles in biological activity) have been focusing their attention mostly on a central biological clock sitting in the hypothalamus and on the genes in charge of it (Borbély et al 2016; Rutter et al 2002). To keep track of time, the clock accumulates certain chemicals until a threshold is reached and then it starts afresh. Presumably, this central clock allows organisms to prepare for, rather than merely react to, recurring changes in light and temperature, so that they can anticipate opportunities to eat and engage in fruitful activities. To this effect, it adjusts the release of hormones that are responsible for one's inclination to eat during the day and sleep during the night (Laje et al 2018). Although it induces a sleep/wake cycle regardless of the external, night/day one, the clock manages to keep the two cycles in sync by using a report, issued by our eyes, of the changes in overall illumination.

If people are given full control over artificial lighting but are deprived of natural light, their patterns of eating, moving, and sleeping change-sometimes drastically, with wake periods shorter than 12 hours or longer than 30 (Aschoff et al 1986). Remarkably, these alterations mirror changes in energy intake and expenditure (Borbély et al 2016; Reddy and Rey 2014). People who spontaneously slow down their day from 24 to 48 hours, for example, proportionally slow down their food intake from three meals per 24-hour day to three per 48hour day (Aschoff et al 1986; Green et al 1987). Their total amount of activity slows down proportionally too (Aschoff 1993). In these conditions, "warmer" people (those whose mean body temperature is higher) tend to shorten their sleep/wake cycle whilst "cooler" people tend to lengthen it (Daan et al 2013). A tiny variation in core temperature $\left(0.5^{\circ} \mathrm{C}\right)$ corresponds to hugely different individual day lengths - spanning from 16 to 48 hours. This agrees with the notion that the alternation of sleep and wake strongly depends on energy management.

The central clock regulates other clocks that are stationed throughout the body-in the liver, in the heart and such. Both the central clock and these local ones speed up when the level of an important nutrient-sensing (and growth-promoting) enzyme rises, and slow down when it falls (shown in mice: Ramanathan et al 2018). Exposure to light can reset one's central clock, and interestingly it does so, at least in part, via this same nutrient-sensing enzyme; inhibiting the enzyme blocks this reset (Cao et al 2010; see also Cao et al 2008). 
Indeed, energy management may be more important for keeping track of time than any central or local clocks. In red blood cells kept in vitro in complete darkness, for example, the activity of antioxidant mechanisms and the level of ATP turn out to wax and wane with a 24hour circadian rhythm (O'Neill and Reddy 2011). This is an impressive finding, because red blood cells lack a nucleus and with it the genes necessary to maintain a local clock; sitting in a Petri dish, they cannot possibly be affected by a central brain clock either-which suggests that biorhythms are driven by energy production per se.

Red blood cells lack not only a nucleus but mitochondria too; they rely on an alternative, less efficient source of energy. In most of our cells, however, it is primarily the mitochondria that produce energy. One may thus suppose that it is primarily the mitochondria that control our biorhythms, including the sleep/wake cycle. Consistent with this idea, rats whose brain is infused with low levels of a free-radical-producing chemical fall asleep more often and sleep longer (Ikeda et al 2005).

The burning of digested food in mitochondria increases and decreases with recurrent ups and downs in food intake and therefore with the alternation of wake and sleep. The cyclic production of energy is accompanied by a cyclic production of free radicals and a cyclic need to neutralize them, and it appears that sleep is part of a larger mechanism to accomplish this feat (Ikeda et al 2005). As a matter of fact, glutathione - an important antioxidant in many organisms-induces sleep (Inoué et al 1995) and melatonin-a well-known inducer of sleep - is not only a hormone but also an antioxidant. Melatonin is plentiful in mitochondria, and it has been argued that the bacterial ancestors of mitochondria might have produced melatonin as an antioxidant before it ever became a sleep hormone in creatures like us (Reiter et al 2017).

The importance of our biorhythms is well illustrated by what happens when we mess with them. The invention of artificial light has allowed people to be active any time of day or night. Yet, whether it is due to going to bed too late, to jet lag, or most prominently to shift work, being awake or asleep at the wrong time has been associated with a myriad physical and mental disorders, including anxiety, depression, obesity, heart disease, and cancer (Kondratova and Kondratov 2012; Liu and Chung 2015; Roenneberg and Merrow 2016). Reversing the sleep/wake cycle of human volunteers for just two days disrupts the normal levels and daily variation patterns of more than 100 proteins in the blood, including several that are involved in the regulation of blood sugar, weight gain, immune function, and cancer (Depner et al 2018).

\section{Coda: Have your cake or eat it}

Mitochondria produce nearly all of the energy we animals need. We have evolved to invest this energy to grow, find food and shelter, and leave descendants, and to last long enough to make it all happen. Yet because the continuous manufacturing of energy is inevitably linked to wear-and-tear, mitochondria give us death as well as life. And because energy spent on growing and procreating is energy not spent on recycling and repairing, producing many offspring and living a long life trade off with each other.

What compromises are made in our own special case (how large we become, how early we can reproduce, whether we happen to be born women or men, or for that matter pigeons or rats) is very largely beyond our control. So is the unappetizing truth that hordes of uninvited guests (microbes, viruses, and other selfish entities) are feasting on our resources too, shaping all along how we function and behave (Kramer and Bressan 2015). What we can do is treat our mitochondria as allies and adjust our lifestyle so as to take good care of their 
necessities. By eating properly, exercising regularly, and sleeping at night, we can keep our companions' proton pumps well oiled and their ATP synthases plugging away. We may get in exchange the energy we need to live interestingly.

\section{References}

Adler MI, Bonduriansky R (2014) Why do the well-fed appear to die young? Bioessays 36:439450. doi:10.1002/bies.201300165

Allen JF (1996) Separate sexes and the mitochondrial theory of ageing. J Theor Biol 180:135140. doi:10.1006/jtbi.1996.0089

Allen JF, de Paula WBM (2013) Mitochondrial genome function and maternal inheritance. Biochem Soc Trans 41:1298-1304. doi:10.1042/BST20130106

Angajala A, Lim S, Phillips JB et al (2018) Diverse roles of mitochondria in immune responses: novel insights into immuno-metabolism. Front Immunol 9:1605. doi:10.3389/fimmu.2018.01605

Anthony TG, Morrison CD, Gettys TW (2013) Remodeling of lipid metabolism by dietary restriction of essential amino acids. Diabetes 62:2635-2644. doi:10.2337/db12-1613

Aschoff J (1993) On the relationship between motor activity and the sleep-wake cycle in humans during temporal isolation. J Biol Rhythms 8:33-46. doi:10.1177/074873049300800103

Aschoff J, von Goetz C, Wildgruber C et al (1986) Meal timing in humans during isolation without time cues. J Biol Rhythms 1:151-162. doi:10.1177/074873048600100206

Banerjee R, Chiku T, Kabil O et al (2015) Assay methods for H2S biogenesis and catabolism enzymes. In: Cadenas E, Packer L (eds) Hydrogen sulfide in redox biology, Part A. Methods in Enzymology, vol 554. Elsevier, Amsterdam, pp 189-200

Barja G (2013) Updating the mitochondrial free radical theory of aging: an integrated view, key aspects, and confounding concepts. Antioxid Redox Signal 19:1420-1445. doi:10.1089/ars.2012.5148

Bartke A (2017) Somatic growth, aging, and longevity. NPJ Aging Mech Dis 3:14. doi:10.1038/s41514-017-0014-y

Bartke A, Sun LY, Longo V (2013) Somatotropic signaling: trade-offs between growth, reproductive development, and longevity. Physiol Rev 93:571-598. doi:10.1152/physrev.00006.2012

Bastiaanssen TF, Cowan CS, Claesson MJ et al (2018) Making sense of... the microbiome in psychiatry. Int J Neuropsychoph, pyy067. doi:10.1093/ijnp/pyy067/25437947/pyy067.pdf

Björkman M, Klingen I, Birch AN et al (2011) Phytochemicals of Brassicaceae in plant protection and human health - influences of climate, environment and agronomic practice. Phytochemistry 72:538-556. doi:10.1016/j.phytochem.2011.01.014

Blachier F, Mariotti F, Huneau JF et al (2007) Effects of amino acid-derived luminal metabolites on the colonic epithelium and physiopathological consequences. Amino Acids 33:547-562. doi:10.1007/s00726-006-0477-9

Blagosklonny MV (2013) Big mice die young but large animals live longer. Aging 5:227-233. doi:10.18632/aging.100551

Borbély AA, Daan S, Wirz-Justice A et al (2016) The two-process model of sleep regulation: a reappraisal. J Sleep Res 25:131-143. doi:10.1111/jsr.12371

Boyer PD (1975) A model for conformational coupling of membrane potential and proton translocation to ATP synthesis and to active transport. FEBS Lett 58:1-6.

Branco AF, Ferreira A, Simões RF et al (2016) Ketogenic diets: from cancer to mitochondrial diseases and beyond. Eur J Clin Invest 46:285-298. doi:10.1111/eci.12591

Brand MD, Couture P, Else PL et al (1991) Evolution of energy metabolism. Proton permeability of the inner membrane of liver mitochondria is greater in a mammal than in a reptile. Biochem J 275:81-86. 
Bressan P (2018) Inside a mitochondrion [Figure]. Figshare. doi: 10.6084/m9.figshare.6877205 https://figshare.com/s/5d90908b41fe3524efc0.

Bressan P, Kramer P (2016) Bread and other edible agents of mental disease. Front Hum Neurosci 10:130.

Camberos-Luna L, Gerónimo-Olvera C, Montiel T et al (2016) The ketone body, $\beta$ hydroxybutyrate stimulates the autophagic flux and prevents neuronal death induced by glucose deprivation in cortical cultured neurons. Neurochem Res 41:600-609. doi:10.1007/s11064-015-1700-4

Camus MF, Wolf JB, Morrow EH et al (2015) Single nucleotides in the mtDNA sequence modify mitochondrial molecular function and are associated with sex-specific effects on fertility and aging. Curr Biol 25:2717-2722. doi:10.1016/j.cub.2015.09.012

Cann RL, Stoneking M, Wilson AC (1987) Mitochondrial DNA and human evolution. Nature 325:31-36. doi:10.1038/325031a0

Cao R, Lee B, Cho H-Y et al (2008) Photic regulation of the mTOR signaling pathway in the suprachiasmatic circadian clock. Mol Cell Neurosci 38:312-324. doi:10.1016/j.mcn.2008.03.005

Cao R, Li A, Cho H-Y et al (2010) Mammalian target of rapamycin signaling modulates photic entrainment of the suprachiasmatic circadian clock. J Neurosci 30:6302-6314. doi:10.1523/jneurosci.5482-09.2010

Cao X, Zhao Z-W, Zhou H-Y et al (2012) Effects of exercise intensity on copy number and mutations of mitochondrial DNA in gastrocnemus muscles in mice. Mol Med Rep 6:426428. doi:10.3892/mmr.2012.913

Clark A, Mach N (2017) The crosstalk between the gut microbiota and mitochondria during exercise. Front Physiol 8:319. doi:10.3389/fphys.2017.00319

Daan S, Honma S, Honma K-I (2013) Body temperature predicts the direction of internal desynchronization in humans isolated from time cues. J Biol Rhythm 28:403-411. doi:10.1177/0748730413514357

de Paula WBM, Lucas CH, Agip A-NA et al (2013) Energy, ageing, fidelity and sex: oocyte mitochondrial DNA as a protected genetic template. Philos Trans R Soc Lond B Biol Sci 368: 20120263. doi:10.1098/rstb.2012.0263

Depner CM, Melanson EL, McHill AW et al (2018) Mistimed food intake and sleep alters 24hour time-of-day patterns of the human plasma proteome. Proc Natl Acad Sci USA 115:E5390-E5399. doi:10.1073/pnas.1714813115

Dong Z, Sinha R, Richie JP (2018) Disease prevention and delayed aging by dietary sulfur amino acid restriction: translational implications. Ann N Y Acad Sci 1418:44-55. doi:10.1111/nyas. 13584

Ellison PT (2017) Endocrinology, energetics, and human life history: a synthetic model. Horm Behav 91:97-106. doi:10.1016/j.yhbeh.2016.09.006

Fontana L, Partridge L, Longo VD (2010) Extending healthy life span - from yeast to humans. Science 328:321-326. doi:10.1126/science.1172539

Forney LA, Stone KP, Wanders D et al (2017a) Sensing and signaling mechanisms linking dietary methionine restriction to the behavioral and physiological components of the response. Front Neuroendocrinol [Epub ahead of print]. doi:10.1016/j.yfrne.2017.12.002

Forney LA, Wanders D, Stone KP et al (2017b) Concentration-dependent linkage of dietary methionine restriction to the components of its metabolic phenotype. Obesity 25:730-738. doi:10.1002/oby.21806

Gano LB, Patel M, Rho JM (2014) Ketogenic diets, mitochondria, and neurological diseases. J Lipid Res 55:2211-2228.

Gilbert JA, Quinn RA, Debelius J et al (2016) Microbiome-wide association studies link dynamic microbial consortia to disease. Nature 535:94-103. doi:10.1038/nature18850 
Goto S, Naito H, Kaneko T et al (2007) Hormetic effects of regular exercise in aging: correlation with oxidative stress. Appl Physiol Nutr Metab 32:948-953. doi:10.1139/H07-092

Gradari S, Pallé A, McGreevy KR et al (2016) Can exercise make you smarter, happier, and have more neurons? A hormetic perspective. Front Neurosci 10: 93. doi:10.3389/fnins.2016.00093

Green J, Pollak CP, Smith GP (1987) Meal size and intermeal interval in human subjects in time isolation. Physiol Behav 41:141-147.

Haldane JBS (1926) On being the right size. Harper's Magazine 152:424-427.

Hao S, Sharp JW, Ross-Inta CM et al (2005) Uncharged tRNA and sensing of amino acid deficiency in mammalian piriform cortex. Science 307:1776-1778. doi:10.1126/science. 1104882

Hasek BE, Stewart LK, Henagan TM et al (2010) Dietary methionine restriction enhances metabolic flexibility and increases uncoupled respiration in both fed and fasted states. Am J Physiol-Reg I 299:R728-R739. doi:10.1152/ajpregu.00837.2009

He F, Li J, Liu Z et al (2016) Redox mechanism of reactive oxygen species in exercise. Front Physiol 7:486. doi:10.3389/fphys.2016.00486

He Q, Morris BJ, Grove JS et al (2014) Shorter men live longer: association of height with longevity and FOXO3 genotype in American men of Japanese ancestry. PLoS ONE 9: e94385. doi:10.1371/journal.pone.0094385

Herbert M, Turnbull D (2018) Progress in mitochondrial replacement therapies. Nat Rev Mol Cell Biol 19:71-72. doi:10.1038/nrm.2018.3

Hernández-Julián R, Mansour H, Peters C (2014) The effects of intrauterine malnutrition on birth and fertility outcomes: evidence from the 1974 Bangladesh famine. Demography 51:17751796. doi:10.1007/s 13524-014-0326-5

Herrero A, Barja G (1997) ADP-regulation of mitochondrial free radical production is different with complex I- or complex II-linked substrates: implications for the exercise paradox and brain hypermetabolism. J Bioenerg Biomembr 29:241-249.

Hiendleder S (2007) Mitochondrial DNA inheritance after SCNT. Adv Exp Med Biol 591:103116. doi:10.1007/978-0-387-37754-4_8

Hirose M, Künstner A, Schilf P et al (2017) Mitochondrial gene polymorphism is associated with gut microbial communities in mice. Sci Rep 7:15293. doi:10.1038/s41598-017-15377-7

Hood DA, Uguccioni G, Vainshtein A et al (2011) Mechanisms of exercise-induced mitochondrial biogenesis in skeletal muscle: implications for health and disease. Compr Physiol 1:1119-1134. doi:10.1002/cphy.c100074

Hugon P, Dufour J-C, Colson P et al (2015) A comprehensive repertoire of prokaryotic species identified in human beings. Lancet Infect Dis 15:1211-1219. doi:10.1016/s14733099(15)00293-5

Hull KL, Harvey S (2014) Growth hormone and reproduction: a review of endocrine and autocrine/paracrine interactions. Int J Endocrinol 2014:1-24. doi:10.1155/2014/234014

Ikeda M, Ikeda-Sagara M, Okada T et al (2005) Brain oxidation is an initial process in sleep induction. Neuroscience 130:1029-1040. doi:10.1016/j.neuroscience.2004.09.057

Inoué S, Honda K, Komoda Y (1995) Sleep as neuronal detoxification and restitution. Behav Brain Res 69:91-96.

Jansen RP (2000) Germline passage of mitochondria: quantitative considerations and possible embryological sequelae. Hum Reprod 15 Suppl 2:112-128.

Johnston IG, Williams BP (2016) Evolutionary inference across eukaryotes identifies specific pressures favoring mitochondrial gene retention. Cell Syst 2:101-111. doi:10.1016/j.cels.2016.01.013 
Kalghatgi S, Spina CS, Costello JC et al (2013) Bactericidal antibiotics induce mitochondrial dysfunction and oxidative damage in mammalian cells. Sci Transl Med 5:192ra85-192ra85. doi:10.1126/scitranslmed.3006055

Karami-Mohajeri S, Abdollahi M (2013) Mitochondrial dysfunction and organophosphorus compounds. Toxicol Appl Pharmacol 270:39-44. doi:10.1016/j.taap.2013.04.001

Kauppila JH, Stewart JB (2015) Mitochondrial DNA: radically free of free-radical driven mutations. Biochim Biophys Acta 1847:1354-1361. doi:10.1016/j.bbabio.2015.06.001

Keeney KM, Yurist-Doutsch S, Arrieta MC et al (2014) Effects of antibiotics on human microbiota and subsequent disease. Annu Rev Microbiol 68:217-235. doi:10.1146/annurevmicro-091313-103456

Kellingray L, Tapp HS, Saha S et al (2017) Consumption of a diet rich in Brassica vegetables is associated with a reduced abundance of sulphate-reducing bacteria: a randomised crossover study. Mol Nutr Food Res 61:1600992. doi:10.1002/mnfr.201600992

Klein EY, Van Boeckel TP, Martinez EM et al (2018) Global increase and geographic convergence in antibiotic consumption between 2000 and 2015. Proc Natl Acad Sci USA 115:E3463-E3470. doi:10.1073/pnas.1717295115

Kondratova AA, Kondratov RV (2012) The circadian clock and pathology of the ageing brain. Nat Rev Neurosci 13:325-335. doi:10.1038/nrn3208

Konjar, Frising UC, Ferreira $\mathrm{C}$ et al (2018) Mitochondria maintain controlled activation state of epithelial-resident $\mathrm{T}$ lymphocytes. Sci Immunol 3:eaan2543. doi:10.1126/sciimmunol.aan2543

Kramer P, Bressan P (2015) Humans as superorganisms: how microbes, viruses, imprinted genes, and other selfish entities shape our behavior. Perspect Psychol Sci 10:464-481. doi:10.1177/1745691615583131

Kramer P, Bressan P (2018) Our (mother's) mitochondria and our mind. Perspect Psychol Sci 13:88-100. doi:10.1177/174569161771835

Laje R, Agostino PV, Golombek DA (2018) The times of our lives: interaction among different biological periodicities. Front Integr Neurosci 12:10. doi:10.3389/fnint.2018.00010

Lane N (2005) Power, sex, suicide: mitochondria and the meaning of life. Oxford University Press, Oxford.

Lane N (2011) The costs of breathing. Science 334:184-185. doi:10.1126/science.1214012

Lane N (2015) The vital question: why is life the way it is? Profile Books, London.

Lemaître JF, Berger V, Bonenfant C et al (2015) Early-late life trade-offs and the evolution of ageing in the wild. Proc Biol Sci 282:20150209. doi:10.1098/rspb.2015.0209

Lewin N, Swanson EM, Williams BL et al (2017) Juvenile concentrations of IGF-1 predict lifehistory trade-offs in a wild mammal. Funct Ecol 31:894-902. doi:10.1111/1365-2435.12808

Linden DR (2014) Hydrogen sulfide signaling in the gastrointestinal tract. Antioxid Redox Signal 20:818-830. doi:10.1089/ars.2013.5312

Liu C, Chung M (2015) Genetics and epigenetics of circadian rhythms and their potential roles in neuropsychiatric disorders. Neurosci Bull 31:141-159. doi:10.1007/s12264-014-1495-3

Longo VD, Mattson MP (2014) Fasting: molecular mechanisms and clinical applications. Cell Metab 19:181-192. doi:10.1016/j.cmet.2013.12.008

López-Armada MJ, Riveiro-Naveira RR, Vaamonde-García C et al (2013) Mitochondrial dysfunction and the inflammatory response. Mitochondrion 13:106-118. doi:10.1016/j.mito.2013.01.003

López-Torres M, Barja G (2008) Lowered methionine ingestion as responsible for the decrease in rodent mitochondrial oxidative stress in protein and dietary restriction. Biochim Biophys Acta 1780:1337-1347. doi:10.1016/j.bbagen.2008.01.007

Martin WF, Neukirchen S, Zimorski V et al (2016) Energy for two: new archaeal lineages and the origin of mitochondria. Bioessays 38:850-856. doi:10.1002/bies.201600089 
Martínez-Redondo D, Marcuello A, Casajús JA et al (2010) Human mitochondrial haplogroup H: the highest VO2max consumer - is it a paradox? Mitochondrion 10:102-107. doi:10.1016/j.mito.2009.11.005

Maruszak A, Adamczyk JG, Siewierski M et al (2014) Mitochondrial DNA variation is associated with elite athletic status in the Polish population. Scand J Med Sci Spor 24:311318. doi:10.1111/sms.12012

Matheu A, Maraver A, Klatt P et al (2007) Delayed ageing through damage protection by the Arf/p53 pathway. Nature 448:375-379. doi:10.1038/nature05949

Merry TL, Ristow M (2016) Do antioxidant supplements interfere with skeletal muscle adaptation to exercise training? J Physiol 594:5135-5147. doi:10.1113/jp270654

Meyer JN, Leung MC, Rooney JP et al (2013) Mitochondria as a target of environmental toxicants. Toxicol Sci 134:1-17. doi:10.1093/toxsci/kft102

Miller VJ, Villamena FA, Volek JS (2018) Nutritional ketosis and mitohormesis: potential implications for mitochondrial function and human health. J Nutr Metab 2018:1-27. doi:10.1155/2018/5157645

Mostafalou S, Abdollahi M (2013) Pesticides and human chronic diseases: evidences, mechanisms, and perspectives. Toxicol Appl Pharm 268:157-177. doi:10.1016/j.taap.2013.01.025

Mottawea W, Chiang C-K, Mühlbauer M et al (2016) Altered intestinal microbiota-host mitochondria crosstalk in new onset Crohn's disease. Nat Commun 7:13419. doi:10.1038/ncomms13419

Myers JH (1978) Sex ratio adjustment under food stress: maximization of quality or numbers of offspring. Am Nat 112:381-388.

Navara KJ (2014) Low gestational weight gain skews human sex ratios towards females. PLoS ONE 9:e114304. doi:10.1371/journal.pone.0114304

Newman JC, Verdin E (2014) Ketone bodies as signaling metabolites. Trends Endocrin Met 25:42-52. doi:10.1016/j.tem.2013.09.002

Omote H, Sambonmatsu N, Saito K et al (1999) The $\gamma$-subunit rotation and torque generation in F1-ATPase from wild-type or uncoupled mutant Escherichia coli. Proc Natl Acad Sci USA 96:7780-7784.

O’Neill JS, Reddy AB (2011) Circadian clocks in human red blood cells. Nature 469:498-503. doi:10.1038/nature09702

Pal VK, Bandyopadhyay P, Singh A (2018) Hydrogen sulfide in physiology and pathogenesis of bacteria and viruses. IUBMB Life 70:393-410. doi:10.1002/iub.1740

Pamplona R, Barja G (2006) Mitochondrial oxidative stress, aging and caloric restriction: the protein and methionine connection. Biochim Biophys Acta 1757:496-508. doi:10.1016/j.bbabio.2006.01.009

Penn DJ, Smith KR (2007) Differential fitness costs of reproduction between the sexes. Proc Natl Acad Sci USA 104:553-558. doi:10.1073/pnas.0609301103

Peternelj TT, Coombes JS (2011) Antioxidant supplementation during exercise training: beneficial or detrimental? Sports Med 41:1043-1069. doi:10.2165/11594400-00000000000000

Pitnick S, Karr TL (1998) Paternal products and by-products in Drosophila development. Proc Biol Sci 265:821-826. doi:10.1098/rspb.1998.0366

Powers SK, Jackson MJ (2008) Exercise-induced oxidative stress: cellular mechanisms and impact on muscle force production. Physiol Rev 88:1243-1276. doi:10.1152/physrev.00031.2007

Pyle A, Hudson G, Wilson IJ et al (2015) Extreme-depth re-sequencing of mitochondrial DNA finds no evidence of paternal transmission in humans. PLoS Genet 11:e1005040. doi:10.1371/journal.pgen.1005040 
Radak Z, Chung HY, Koltai E et al (2008) Exercise, oxidative stress and hormesis. Ageing Res Rev 7:34-42. doi:10.1016/j.arr.2007.04.004

Radak Z, Ishihara K, Tekus E et al (2017) Exercise, oxidants, and antioxidants change the shape of the bell-shaped hormesis curve. Redox Biol 12:285-290. doi:10.1016/j.redox.2017.02.015

Radak Z, Zhao Z, Koltai E et al (2013) Oxygen consumption and usage during physical exercise: the balance between oxidative stress and ROS-dependent adaptive signaling. Antioxid Redox Signal 18:1208-1246. doi:10.1089/ars.2011.4498

Rahman J, Rahman S (2018) Mitochondrial medicine in the omics era. Lancet 391:2560-2574. doi:10.1016/S0140-6736(18)30727-X

Ramanathan C, Kathale ND, Liu D et al (2018) mTOR signaling regulates central and peripheral circadian clock function. PLoS Genet 14:e1007369. doi:10.1371/journal.pgen.1007369

Reddy AB, Rey G (2014) Metabolic and nontranscriptional circadian clocks: eukaryotes. Annu Rev Biochem 83:165-189. doi:10.1146/annurev-biochem-060713-035623

Redman LM, Smith SR, Burton JH et al (2018) Metabolic slowing and reduced oxidative damage with sustained caloric restriction support the rate of living and oxidative damage theories of aging. Cell Metab 27:805-815.e4. doi:10.1016/j.cmet.2018.02.019

Reiter RJ, Rosales-Corral S, Tan DX et al (2017) Melatonin as a mitochondria-targeted antioxidant: one of evolution's best ideas. Cell Mol Life Sci 74:3863-3881. doi:10.1007/s00018-017-2609-7

Rich P (2003) The cost of living. Nature 421:583. doi:10.1038/421583a

Ristow M, Zarse K, Oberbach A et al (2009) Antioxidants prevent health-promoting effects of physical exercise in humans. Proc Natl Acad Sci USA 106:8665-8670. doi:10.1073/pnas.0903485106

Roenneberg T, Merrow M (2016) The circadian clock and human health. Curr Biol 26:R432R443. doi:10.1016/j.cub.2016.04.011

Rogers GB, Keating DJ, Young RL et al (2016) From gut dysbiosis to altered brain function and mental illness: mechanisms and pathways. Mol Psychiatry 21:738-748. doi:10.1038/mp.2016.50

Rutter J, Reick M, McKnight SL (2002) Metabolism and the control of circadian rhythms. Annu Rev Biochem 71:307-331. doi:10.1146/annurev.biochem.71.090501.142857

Sato M, Sato K (2013) Maternal inheritance of mitochondrial DNA by diverse mechanisms to eliminate paternal mitochondrial DNA. Biochim Biophys Acta 1833:1979-1984. doi:10.1016/j.bbamcr.2013.03.010

Schulz TJ, Zarse K, Voigt A et al (2007) Glucose restriction extends Caenorhabditis elegans life span by inducing mitochondrial respiration and increasing oxidative stress. Cell Metab 6:280-293. doi:10.1016/j.cmet.2007.08.011

Sender R, Fuchs S, Milo R (2016) Revised estimates for the number of human and bacteria cells in the body. PLoS Biol 14:e1002533. doi:10.1371/journal.pbio.1002533

Song S (2012) Does famine influence sex ratio at birth? Evidence from the 1959-1961 Great Leap Forward Famine in China. Proc Biol Sci 279:2883-2890. doi:10.1098/rspb.2012.0320

Song S (2015) Privation, stress, and human sex ratio at birth. Early Hum Dev 91:823-827. doi:10.1016/j.earlhumdev.2015.10.009

Soong RK, Bachand GD, Neves HP et al (2000) Powering an inorganic nanodevice with a biomolecular motor. Science 290:1555-1558.

Stojković B, Sayadi A, Đorđević M et al (2017) Divergent evolution of life span associated with mitochondrial DNA evolution. Evolution 71:160-166. doi:10.1111/evo.13102

Strong M (2004) Protein nanomachines. PLoS Biol 2:e73.

Stuart JA, Page MM (2010) Plasma IGF-1 is negatively correlated with body mass in a comparison of 36 mammalian species. Mech Ageing Dev 131:591-598. doi:10.1016/j.mad.2010.08.005 
Suh Y, Atzmon G, Cho MO et al (2008) Functionally significant insulin-like growth factor I receptor mutations in centenarians. Proc Natl Acad Sci USA 105:3438-3442. doi:10.1073/pnas.0705467105

Sulak M, Fong L, Mika K et al (2016) TP53 copy number expansion is associated with the evolution of increased body size and an enhanced DNA damage response in elephants. Elife 5:e11994.

Sutovsky P, Moreno RD, Ramalho-Santos J et al (1999) Ubiquitin tag for sperm mitochondria. Nature 402:371-372. doi:10.1038/46466

Swanson EM, Dantzer B (2014) Insulin-like growth factor-1 is associated with life-history variation across Mammalia. Proc R Soc Lond B Biol Sci 281:20132458. doi:10.1098/rspb.2013.2458

Tabatabaie V, Atzmon G, Rajpathak SN et al (2011) Exceptional longevity is associated with decreased reproduction. Aging 3:1202-1205. doi:10.18632/aging.100415

Templeman NM, Murphy CT (2018) Regulation of reproduction and longevity by nutrientsensing pathways. J Cell Biol 217:93-106. doi:10.1083/jcb.201707168

Tian X, Seluanov A, Gorbunova V (2017) Molecular mechanisms determining lifespan in shortand long-lived species. Trends Endocrinol Metab 28:722-734. doi:10.1016/j.tem.2017.07.004

Trewin A, Berry B, Wojtovich A (2018) Exercise and mitochondrial dynamics: keeping in shape with ROS and AMPK. Antioxidants 7:7. doi:10.3390/antiox7010007

Trivers RL, Willard DE (1973) Natural selection of parental ability to vary the sex ratio of offspring. Science 179:90-92.

Ueno H, Suzuki T, Kinosita K et al (2005) ATP-driven stepwise rotation of FoF1-ATP synthase. Proc Natl Acad Sci USA 102:1333-1338. doi:10.1073/pnas.0407857102

Villanueva C, Kross RD (2012) Antioxidant-induced stress. Int J Mol Sci 13:2091-2109. doi:10.3390/ijms13022091

Vitale G, Brugts MP, Ogliari G et al (2012) Low circulating IGF-I bioactivity is associated with human longevity: findings in centenarians' offspring. Aging 4:580-589. doi:10.18632/aging.100484

Wallace DC (2005) A mitochondrial paradigm of metabolic and degenerative diseases, aging, and cancer: a dawn for evolutionary medicine. Annu Rev Genet 39:359-407. doi:10.1146/annurev.genet.39.110304.095751

Wanders D, Burk DH, Cortez CC et al (2015) UCP1 is an essential mediator of the effects of methionine restriction on energy balance but not insulin sensitivity. FASEB J 29:2603-2615. doi:10.1096/fj.14-270348

Wang X, Ryu D, Houtkooper RH et al (2015) Antibiotic use and abuse: a threat to mitochondria and chloroplasts with impact on research, health, and environment. Bioessays 37:1045-1053. doi:10.1002/bies.201500071

Yao CK, Muir JG, Gibson PR (2016) Review article: insights into colonic protein fermentation, its modulation and potential health implications. Aliment Pharmacol Ther 43:181-196. doi:10.1111/apt.13456

Zarse K, Schmeisser S, Groth M et al (2012) Impaired insulin/IGF1 signaling extends life span by promoting mitochondrial L-proline catabolism to induce a transient ROS signal. Cell Metab 15:451-465. doi:10.1016/j.cmet.2012.02.013 